\title{
Batman y Miguel Ángel: algunas consideraciones sobre el arte moderno y el arte posmoderno.
}

\section{Batman and Michelangelo: some considerations on modern art and postmodern art.}

\author{
Mauricio Méndez Huerta* \\ Departamento de Filosofía / Universidad de Guadalajara (MÉXICO) \\ CE: mauricio.mendez@academicos.udg.mx ID ORCID: 0000-0002-7283-8051 \\ José María Nava Preciado** \\ Departamento de Filosofía / Universidad de Guadalajara (MÉXICO) \\ CE: jnava preciado@yahoo.com.mx ID ORCID: 0000-0003-2050-1251
}

DOI: $10.32870 /$ sincronia.axxiii.n76.2b19

$\mathrm{BY} \cdot \mathrm{NC}$

Esta obra está bajo una Licencia Creative Commons Atribución-NoComercial 4.0 Internacional

\begin{abstract}
* Maestro en Lingüística Aplicada y estudiante del Doctorado en Humanidades por la Universidad de Guadalajara. Profesor asociado «A» del Departamento de Filosofía de la Universidad de Guadalajara, miembro del Cuerpo Académico Retórica, Lógica y Teoría de la Argumentación. Reasercher ID: N-9554-2017. Orcid: 0000-0002-7283-8051

** Doctor en Educación por la Universidad Pedagógica Nacional (UPN). Profesor titular «C» del Departamento de Filosofía de la Universidad de Guadalajara, miembro del SNI, nivel I, Researcher ID: L-5260-2017. Orcid: 0000-00032050-1251
\end{abstract}

Recibido: $10 / 01 / 2019$

Revisado: $21 / 02 / 2019$

Aprobado: $17 / 05 / 2019$

\section{RESUMEN}

La finalidad del artículo es presentar una primera aproximación teórico-interpretativa, en términos comparativos, entre el arte moderno y el arte posmoderno, a partir de elementos del discurso (la textualidad) que acompañan a la modernidad y la posmodernidad. El pre-texto de la discusión se da 
en torno a una obra de arte renacentista y una obra de arte posmoderna, obras que fueron creadas bajo cánones artísticos considerados por la tradición como opuestos. Se propone un modelo inicial (pre-modelo) de acercamiento a las categorías de "arte moderno" y "arte posmoderno", fundado en la noción de prototipo y considerando algunos tratamientos teóricos desprendidos de la lingüística funcional. El planteamiento central del presente artículo es el siguiente: la modernidad y la posmodernidad pueden ser entendidas como opuestos dialécticos en el sentido de que ocupan los lugares polares a lo largo de un continuo (continuum), en el cual encontramos las más diversas denominaciones en lo que a arte se refiere, diferenciándose ellas gradualmente a partir de un conjunto de características que pueden fungir como "criterios" o "parámetros".

Palabras clave: Arte. Modernidad. Posmodernidad. Batman. Miguel Ángel.

\begin{abstract}
:
The aim of the article is to present a first theoretical-interpretative approach on the contrast between modern art and postmodern, defining modernity and postmodernity from the discursive elements (textuality) that justify them. The pre-text of the discussion arises around a work of Renaissance art and a work of postmodern art. These works were created under artistic canons, considered by tradition as opposites. An initial model (pre-model) of approach to the categories of "modern art" and "postmodern art" is proposed, based on the notion of prototype and considering some theoretical treatments detached from functional linguistics. The thesis of this article is the following: modernity and postmodernity can be understood as dialectical opposites in the sense that they occupy the polar places along a continuum, in which we find the most diverse denominations in terms of art styles. These art styles differ from each other gradually by means of a set of characteristics that can act as "criteria" or "parameters".
\end{abstract}

Keywords: Art. Modernity. Postmodernity. Batman. Michelangelo.

Se propone un modelo inicial
arte posmoderno", fundado en
desprendidos de la lingüistica
siguiente: la modernidad y la
el sentido de que ocupan los
gradualmente a partir de un
ngel.
metros".
created under artistic canons,
approach to the categories of
mallive approach on the contrast

Es posible que parecer - sea ser, como el sol es algo aparente y es.

El sol es un ejemplo. Lo que aparenta es y en tal apariencia todas las cosas son. Wallace Stevens $\left(1945\right.$, p. 559) ${ }^{1}$

\footnotetext{
${ }^{1}$ La traducción es nuestra. El texto original en inglés es el siguiente:
} 


\section{El pre-texto}

Como si se tratara de la repetición de los arquetipos platónicos, eternos y seductores, la conciencia humana, a lo largo de su desarrollo histórico, se ha venido configurando a partir de oposiciones, no necesariamente dialécticas, en todos los ámbitos de su existencia: la perenne lucha entre el bien y el mal, que aparece, matizada, tanto en Oriente como en Occidente; la contraposición entre el poderoso y el débil, a veces pacífica, a veces violenta; las paradójicas relaciones entre el pasado, el presente y el futuro; las exquisitas delicias del mundo y del cuerpo contra los derroteros del espíritu, no menos sibaritas que aquéllos; el enfrentamiento metafóricamente colorido entre la luz del pensamiento y las tinieblas de la ignorancia; la innegable abstracción del litigio entre el ser y el no ser, entre la apariencia y la realidad; la famosa y desgarradora dialéctica entre el amo y el esclavo...

El viejo adagio heraclíteo de la lucha entre los contrarios como principio básico del devenir aplica, sin lugar a dudas, a la polémica, aún rebosante de actualidad, suscitada entre dos paradigmas $^{2}$ que sacuden nuestro "ser contemporáneo" en relación directa a las otrora llamadas ciencias del espíritu, a las ciencias de la naturaleza (Cfr. Dilthey, 1949), al arte, la academia, la tecnología, etcétera: la modernidad y la posmodernidad. Debemos enfatizar el carácter fundamental de ese devenir ya mencionado, dado que permea la propia posición de los que escriben estas líneas frente a esa dicotomía contradictoria: el devenir puede implicar o bien un carácter progresivo o bien un carácter totalmente negativo, al mismo tiempo que supone que los

\footnotetext{
It is possible that to seem-it is to be, As the sun is something seeming and it is.

The sun is an example. What it seems It is and in such seeming all things are.
}

\footnotetext{
2 Podemos entender paradigma en el sentido de Kuhn (1971) como un modelo constituido por un conjunto de valores, creencias, normas, técnicas y prácticas, que son compartidas por una comunidad determinada. Con respecto a esto, los grupos sociales que conviven en una sociedad (nuestra sociedad) pueden ser denominados como "modernos" o como "posmodernos", es decir, coexisten desde sus diversos paradigmas.
} 
opuestos contradictorios se necesitan uno al otro para ser (Cfr. Mondolfo, 1966, pp. 129-165). Partimos de esa idea ante la imposibilidad de llevar a cabo clasificaciones claramente delimitadas, ya sea a la manera del matemático o la manera del físico, sobre lo que sean la modernidad y la posmodernidad.

Al respecto, si Octavio Paz (2014) se refiere con razón a la modernidad como "un expediente, una manera de nombrar lo que todavía no tiene nombre. Nos llamamos "modernos" porque ignoramos nuestro nombre" (p. 531), con mayor razón podemos aplicar las mismas palabras a la posmodernidad misma, dado que, según algunos pensadores, estamos insertos en ella de una u otra manera. Así, la inexistencia de la distancia con respecto al objeto de estudio, nos limita para su total determinación. La conclusión inevitable de lo anterior es que una lógica fundamentada en la dicotomía verdad-falsedad resulta totalmente insuficiente para caracterizar nuestros dos opuestos.

Por semejantes razones, el objetivo del presente artículo se configura como un primer acercamiento teórico-interpretativo, no conclusivo en el sentido de la lógica formal, a las relaciones entre "el arte moderno" y "el arte posmoderno", fundado en la noción de prototipo y que tiene como pretexto la comparación entre una obra de arte renacentista y una obra de arte posmoderno. Por su parte, el planteamiento central del presente artículo es el siguiente: la modernidad y la posmodernidad pueden ser entendidas como opuestos dialécticos en el sentido de que ocupan los lugares polares a lo largo de un continuo (continuum), en el cual encontramos las más diversas denominaciones en lo que a arte se refiere, diferenciándose ellas gradualmente a partir de un conjunto de características que pueden fungir como "criterios" o "parámetros". La noción de continuo, utilizada en lo que sigue, se presenta a semejanza de los modelos de la lingüística funcional ligada al Proyecto de Universales y Tipología de la Universidad de Colonia para explicar determinados fenómenos lingüísticos que son difícilmente explicados por categorías absolutas (Cfr. Seiler, 2001, pp. 323-344 y Oesterreicher, 2004) $)^{3}$.

\footnotetext{
${ }^{3}$ Se pone en cursivas la palabra "semejanza" para enfatizar que no se siguen al pie de la letra los modelos lingüísticos mencionados, sino que se utiliza específicamente la idea del continuo como una forma de interpretar determinados fenómenos en términos graduales, dejando de lado los fundamentos cognitivos, operacionales y pragmáticos que constituyen tales planteamientos teóricos. (Cfr. Wittgenstein, 1988).
} 


\section{El texto de lo moderno como negación del arte renacentista: el caso de Miguel Ángel}

Al término de la antigüedad griega y romana, como etapas históricas, adviene un período que se ha concebido, quizás con cierta razón, bajo el rasgo semántico de la oscuridad: la Edad Media, caracterizada por tener como eje de su ser el libro Sagrado, la obra aristotélica y la Biblia, como forma de interpretación del mundo. La persecución de hombres de ciencia y el dogma como manera predilecta del discurso eran prácticas cotidianas. El propio arte se encontraba entonces adscrito a las formas religiosas, ya geometrizadas, ya naturalizadas. Esa condición ontológica de oscuridad, para devenir en otra cosa, requiere de un renacimiento y de la oposición con su némesis, las luces, ilustradas y optimistas, el derrocamiento mismo de la cosmovisión escolástica a través de la postulación de un discurso metodológico radicalmente diferente de cepa cartesiana, la redondez de la tierra y la invención de América (Cfr. O’Gorman, 1984), Gutenberg tras bambalinas, la sustitución del amo por el burgués, del ciervo por el proletario, etcétera, etcétera ${ }^{4}$.

De ahí en adelante, no hay pues, motivo para el desencanto; toda la complejidad de los seres humanos es explicada gracias al desarrollo tecnológico y científico asociado a la racionalidad; la verdad, además de estar conectada inherente y directamente con la ciencia, también se revelará como valor de la actividad artística misma. Por ejemplo:

Entre las obras más importantes de la pintura nunca han faltado aquellas que, aun apuntando a una desintegración, supieron levantar acta contra quienes fueron responsables de ella. Desde Grünewald hasta Dalí, desde el Cristo putrefacto al asno putrefacto... la pintura siempre... ha sido capaz de encontrar nuevas verdades que no eran verdades estrictamente pictóricas. (Crevel, citado por Benjamin, 2013, p. 85).

Esta vinculación entre la pintura, que puede ser generalizada al arte moderno, y el concepto de verdad supone una metafísica del ser y el no-ser. El ser es objetivo, justo, bello, verdadero,

\footnotetext{
${ }^{4}$ Hay varios siglos de evolución en este proceso mencionado en el párrafo.
} 
proporcionado, simétrico, auténtico y, por tanto, debe generar un canon aceptado universalmente ${ }^{5}$. Por su parte, el no-ser es injusto, invalorable estéticamente, falso, amorfo, copia infame; por tanto, debe ser rechazado, también universalmente. Así, en contra de nuestro epígrafe de Wallace Stevens, el no-ser, en tanto que émulo, representa, platónicamente hablando, una mera apariencia carente de substancia, una

Justificación filosófica para el denuesto de la mundanidad. Desde cualquier ángulo que se observe, la copia anhela el original ya que nunca es igual a él. La copia es la suma de los calificativos negativos. El cuerpo es el lugar de la copia, el espíritu simplemente es. Flagelo angélico, promesa fraude, goce sublimado, feromona procrastinada para siempre... El titiritero es siempre auténtico... (Nava y Méndez, 2018, p. 31).

De esta manera, "el arte es", predicado para el arte moderno, implicaría que es perfectamente definible sobre la base de los cánones establecidos por este paradigma, dependientes en muchos sentidos del Renacimiento, y que negaría el ser arte, a su vez, a todo aquello que no se corresponda con: orden, proporción, armonía, ritmo, medida, simetría, perspectiva, etcétera. Por lo tanto, el arte posmoderno, como negación del arte moderno, pertenecería al reino del no-ser.

Si se compara el arte renacentista con el arte moderno (opuesto al "arte académico"), a partir de la oposición ser y no-ser, se encuentra que el primero estaría representado por el ser y el segundo, al ser su negación, estaría representado por el no-ser. Una vez que se institucionaliza el arte moderno, éste se constituye como el canon a seguir, es decir, como el ser. Así, el arte posmoderno, a su vez, representaría el no-ser con respecto al arte posmoderno. Lo que se trata de argumentar en el presente artículo es precisamente que una metafísica del ser y del no-ser no logra dar cuenta de la continuidad ni del cambio paulatino entre un estilo y otro, entre un paradigma y otro.

Esta idea del arte moderno vinculada al ser implica, paradójicamente, la existencia de la innovación y de la experimentación. En ese sentido, en los renacentistas mismos se ubican

\footnotetext{
${ }^{5}$ Referimos aquí, de manera fundamental, al concepto platónico de ser y no-ser, tal y como se expresa en el diálogo del Sofista.
} 
diferencias de técnica y estilo que no pueden ser explicadas exclusivamente desde sus propios cánones; por ejemplo, “En Rafael y Miguel Ángel los objetivos y cánones clásicos se ven desplazados, desde su primera juventud, por tendencia barrocas y manieristas" (Hauser, 1982, p. 20). Este tipo de apreciaciones de los expertos nos conducen a la conclusión de que es sumamente complejo atender a la idea del arte moderno como un paradigma homogéneo. Lo que está implicado, por el contrario, es la existencia de diversas "escuelas", "estilos" o "formas" de hacer arte en un mismo momento histórico, sin perder de vista que las combinaciones son posibles como en el caso arriba señalado.

De la misma manera, por ejemplo, la idea de la individualidad del artista (el titiritero), que aparece ya en el Renacimiento, es enfatizada y exaltada en el arte moderno, en tanto que aquél, ese que produce una obra de arte genial, es un ente con plena consciencia de su ser subjetivo, rasgo fundamental del romanticismo (que convive histórica y paradójicamente con el racionalismo científico ilustrado en auge):

(...) no hay producto del arte moderno, no hay impulso emocional, no hay impresión o disposición de ánimo del hombre moderno, que no deba su sutileza y su variedad a la sensibilidad nerviosa que tiene su origen en el Romanticismo. Toda la exuberancia, la anarquía y la violencia del arte moderno, su lirismo ebrio y balbuciente, su exhibicionismo desenfrenado y desconsiderado proceden del Romanticismo. Y esta actitud subjetiva y egocéntrica se ha vuelto para nosotros tan obvia, tan indispensable, que no podemos ni siquiera reproducir una asociación abstracta de ideas sin hablar de nuestros sentimientos. (Hauser, 1993, p. 342).

¿Significa esto que Miguel Ángel es un romántico, un artista moderno, dado que ya tiene plena consciencia de sí como artista ${ }^{6}$ No hay respuesta categórica ya que el problema radica en pensar, una vez más, la noción de paradigma, como si se constituyera de valoraciones ahistóricas, de cánones eternos e inmutables, conceptualmente cerrados y perfectamente delimitados, como si las

\footnotetext{
${ }^{6}$ La pregunta se hace desde nuestro tiempo, no se parte del supuesto de que el artista, como dominador de la técnica, sea al mismo tiempo un teórico de su propia actividad.
} 
concepciones de los expertos y el propio quehacer del artista permanecieran en un mismo estado y para siempre, como si dependieran del ser inmutable de aquella metafísica de la que se hablaba líneas arriba.

Si se piensa en La creación de Adán, producida de 1508 a 1511, entonces veremos cómo se cumplen los elementos de la metafísica del ser asociada al arte moderno: la obra misma habla por sí sin la necesidad de un mediador que la explique; su ser en sí depende de los recursos técnicos y del saber hacer de su autor; Miguel Ángel expresa su propia auténtica individualidad, su saber y su domino de la técnica, a través de la creación de una obra igualmente auténtica, bella, simétrica y proporcionada (valores objetivos) y en dependencia con los elementos propios de la época. De igual manera, se considera que el espectador, quizás hasta el mismo crítico de arte, permanece al paso del tiempo, sin ser influenciado por las transformaciones históricas. Aunque aquí, a pesar del peso de la obra, reconocida universalmente por los expertos, también queda margen para la interpretación, a pesar de aquella metafísica del ser: ¿es La creación de Adán una mera representación de la creación del mundo y del hombre por obra de Dios? o ¿Miguel Ángel sugería a través de la obra la importancia del ser humano en la construcción del mundo? Claro que las preguntas no implican en absoluto el cuestionamiento del sí mismo de la obra, que vale por lo que es y no por la interpretación que en el espectador genere.

Lo que se quiere sugerir con el ejemplo aducido es precisamente que resulta complicado poder describir y explicar en términos absolutos, más allá de su ubicación cronológica, si la obra $\mathrm{X}$ es renacentista, si la obra Y es moderna o si la obra Z es barroca. Tales caracterizaciones implicarían la postulación de una cierta "pureza", y de una determinación clasificatoria en función de propiedades necesarias y suficientes, lo cual es difícil de sostener justamente por la condición histórica del artista y de sus productos, aún cuando para fines pedagógicos se utilicen etiquetas y categorías que suponen definiciones absolutas y acabadas (una pregunta fundamental al respecto es si la historia del arte necesita, para constituirse como tal, de esas etiquetas). Esto nos conduce a pensar en la mezcla de elementos de diferentes tradiciones que no responden necesariamente a rupturas totales entre ellas, lo que entrañaría una representación gradual, como se anunció líneas arriba, 
cuyos polos podrían ser respectivamente el Renacimiento y el Arte Moderno como ejemplos ideales, es decir, como prototipos ${ }^{7}$, lo que abre la posibilidad de ubicar a lo largo de un continuo los diversos estilos o escuelas (manierismo, barroco, rococó, romanticismo, eclecticismo, art noveau, etc.), que se han desarrollado entre la aparición de aquellos prototipos, a partir del establecimiento de un conjunto de diversos criterios y parámetros ${ }^{8}$. De esta forma, Eleanor Rosch nos dice que "Por prototipos de categorías, generalmente nos referimos a los casos más claros de pertenencia a una categoría, definidos operacionalmente por los juicios de las personas sobre la utilidad de la pertenencia a la categoría" (Rosch, 1978, p. 36) ${ }^{9}$.

El prototipo, pues, se entiende como el miembro ejemplar de una categoría, "el más claro", aquél que es más representativo y distintivo y que, por tanto, es más "provechoso" para que las personas puedan comprender la propia categoría. Esto implica que el prototipo es el miembro que comparte más propiedades con todos los otros miembros de la categoría, al mismo tiempo que las propiedades que comparte con miembros de otras categorías es menor (cfr. Rosch y Mervis, 1975, p. 573). La medición gradual se establecería a partir pues de rasgos asociados a categorías difusas que necesitan de "un más o menos", es decir, de grados de similitud o diferencia con respecto al prototipo. A partir de lo anterior, el modelo propuesto sería representado de la siguiente manera:

Renacimiento

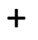

$+$

$-$
Naturalismo

Experimentación

Arte moderno

\footnotetext{
${ }^{7}$ El concepto de prototipo es utilizado en la lingüística cognitiva para ofrecer una explicación de la construcción del significado de ciertas estructuras de la lengua. Para una introducción al concepto véase por ejemplo a Lara, 2006; para una discusión más detallada se puede revisar a Rosch y Lloyd, 1978.

${ }^{8} \mathrm{El}$ (pre)modelo presentado es sólo un acercamiento general para comprender el paso de un estilo a otro en términos graduales y no una representación fiel y exhaustiva de los criterios necesarios y suficientes para definir los estilos, si esto último es posible. Tampoco representa como tal el criterio histórico. Asimismo, enfatizamos que los criterios mismos deben ser definidos y discutidos de manera más detallada, cosa que ocuparía un artículo independiente del presente dada su amplitud.

${ }^{9}$ La traducción es nuestra. El texto original en inglés es el siguiente: "By prototypes of categories we have generally meant the clearest cases of category membership defined operationally by people's judgments of goodness of membership in the category".
} 


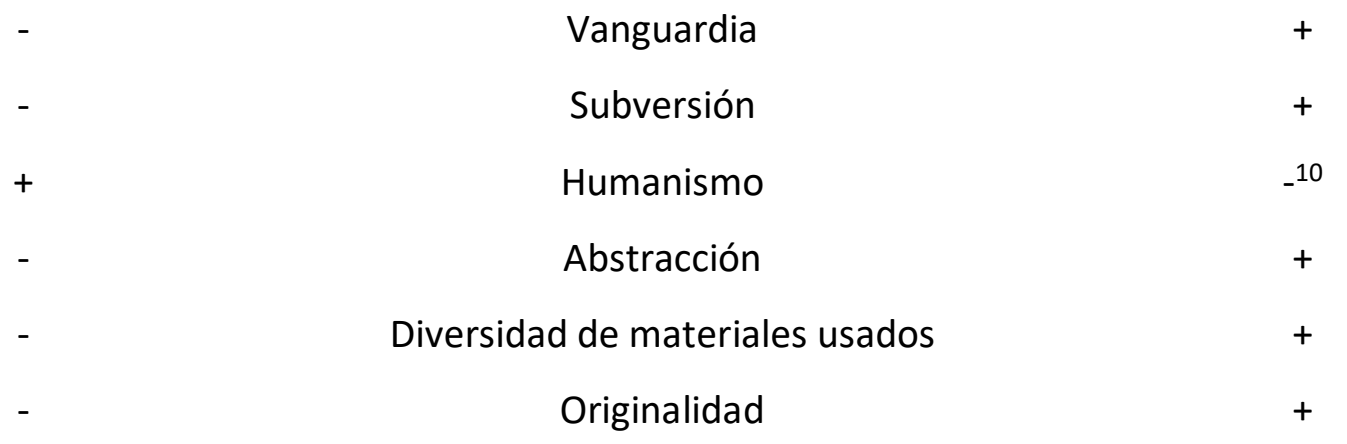

Una de las cuestiones importantes, entre otras, que surgen ante la noción de prototipo y que, por consecuencia, pudieran objetarse frente a este modelo inicial se materializa en preguntas como ¿cuántos prototipos tiene una categoría? ó ¿es sólo un prototipo el que la constituye? y ¿cuántas características tiene un prototipo? Sin embargo, las preguntas suponen la existencia de respuestas basadas en la idea de propiedades y características necesarias y suficientes; tal idea es lo que aquí se intenta justificar como imposible en cuanto a nuestra discusión se refiere. Al respecto de esta problemática, Rosch sostiene que

[...] la noción de prototipos ha tendido a ser reificada, como si se tratara de un miembro específico de la categoría o una estructura mental. Luego, las preguntas se elaboran, de una u otra manera, sobre si algo es o no es el prototipo o parte del prototipo, exactamente del mismo modo en el que se había cuestionado previamente sobre el límite de la categoría. Tal pensamiento viola precisamente el señalamiento wittgensteniniano de que podemos juzgar qué tan claro es un caso cualquiera y tratar con las categorías sobre la base de los casos claros en la total ausencia de información sobre los límites. (Rosch, 1978, p. 36) ${ }^{11}$.

\footnotetext{
${ }^{10}$ El criterio "humanismo" parte de la idea de que fue en el Renacimiento que se ensayó la recuperación de la cultura greco-romana (+), así como de la crítica que hace Ortega y Gasset (1998) al arte moderno (-), quien, de hecho, plantea un conjunto de aspectos que podrían fungir como criterios y que, por cuestión de espacio no se tratan en el presente escrito.

${ }^{11}$ La traducción es nuestra. El texto original en inglés es el siguiente: [...] the notion of prototypes has tended to become reified as though it meant a specific category member or mental structure. Questions are then asked in an either or fashion about whether something is or is not the prototype or part of the prototype in exactly the same way in which the question would previously have been asked about the category boundary. Such thinking precisely violates the
} 
Aquí queda articulada la cercanía conceptual entre prototipo y el parecido de familia de Wittgenstein, para justificar la imposibilidad de definir categorías y conceptos en muchos de los ámbitos en los que los seres humanos nos movemos (Cfr. Wittgenstein, 1988, §60-§ 75). Esta articulación ha influenciado y enriquecido la discusión en torno a la naturaleza de los prototipos, especificando que ellos son modelos idealizados del funcionamiento de la cognición humana, y no de lo que el mundo real es, por lo cual involucran esquematizaciones y simplificaciones que son operativas para el ser humano (Cfr. Lakoff, 1982).

Por tanto, siguiendo el modelo anterior y las explicaciones presentadas, se puede plantear, contra toda lógica dicotómica y exclusiva, una obra prototípica del Renacimiento y una obra prototípica del arte moderno como polos opuestos que recurren a criterios estéticos, sociales, históricos y cognitivos. Esto permitiría ubicar en medio de ambas un conjunto de obras que se acercan gradualmente a uno de los polos en función de los criterios y parámetros que ya fueron señalados:

La creación de Adán

La noche estrellada

En consonancia con los firmes pasos de Heráclito, como se ve, se marca el paso gradual de una concepción a otra, respondiendo a los propios cambios de todo lo existente. En términos históricos, el implacable devenir no ha respetado los principios e ideales de la llamada modernidad, y con ella del Arte Moderno, que se enfrenta ahora a las transformaciones políticas, sociales y, de manera fundamental, al imparable desarrollo de la tecnología, que parece avanzar con los pies de Aquiles ${ }^{12}$.

\footnotetext{
Wittgensteinian insight that we can judge how clear a case something is and deal with categories on the basis of clear cases in the total absence of information about boundaries.

12 La dialéctica supone que la superación de las oposiciones implica la permanencia de aspectos, propiedades o características de los dos opuestos, rasgo que éste que le es inherente a los modelos fundamentados en la idea del continuum.
} 
Ideas como la de emancipación y libertad, el alcance de la plena humanidad y el bienestar social, en suma, la felicidad, se enfrentan a un hecho imprescindible, de naturaleza esencialmente ética, que significó una profunda crisis que, hasta la fecha, no ha sido superada: Auschwitz (Cfr. Lyotard, 1999, pp. 31-74). El continuum se ensancha para dar lugar, paulatinamente, a nuevas formas y a nuevos contenidos...

\section{El texto de lo posmoderno: el caso de Batman}

Aquellos sueños y bailes optimistas de la razón moderna, aquel mundo prometido como el mejor de los mundos posibles, la utopía rediviva de la libertad, la igualdad y la fraternidad se cuestionan con fuerza debido a los desastres de la Segunda Guerra Mundial y al Holocausto Judío llevado a cabo por la Alemania Nazi: el sueño de la razón produce monstruos ${ }^{13}$. La posmodernidad, el saber posmoderno, cuestiona la legitimidad y la validez del discurso científico, a partir de ese monstruoso resultado. La racionalidad científica recurre a un metarrelato que se constituye apelando a los grandes "fines" ético-político-socio-económicos, verbigracia, justicia, democracia, equidad, liberación, libertad, revolución, etcétera. "El rasgo definitorio de la condición posmoderna es, por contraste, la pérdida de credibilidad de esas metanarrativas" (Anderson, 1988, p. 39). El argumento básico que subyace a la crítica a la modernidad elaborada por Lyotard es el siguiente:

Auschwitz representa el fracaso de esa razón científica en tanto que no logra esos "grandes fines": la razón moderna, positiva, no logró conducir a su perfeccionamiento al hombre y a la mujer. Si la ciencia se legitima en un metarrelato y éste se constituye de grandes fines ("emancipación", "felicidad", etc.) entonces la ciencia "debe" lograr esos fines. La ciencia no logra esos fines. Luego, la legitimación de la ciencia en el (meta)relato no es legítima (Méndez y Ramírez, 2017, pp. 99-100).

Aquel cretinismo metafísico de la modernidad en el poder de la razón, de la ciencia, y de su hija la tecnología, como elemento emancipador del ser humano, aquel cretinismo del arte moderno cuya

\footnotetext{
${ }^{13}$ Jugamos con el título de la obra de Goya usándolo como expresión literal del fracaso del proyecto moderno, aunque de hecho parece que el Capricho 43 representa una defensa de la razón por encima de la mera fantasía y la sola imaginación.
} 
profesión de fe se sostenía en una imparable innovación y experimentación, en un constante progreso hacia nuevas y mejores formas, características que son también esenciales del arte moderno (que implica la existencia de sucesivos "modernismos", separados gradualmente y a los que, tradicionalmente, se les reconoce como "vanguardias"), se ven frenados por los millones de muertes en Auschwitz. Quizá se deba decir acelerado porque es precisamente la velocidad uno de los rasgos distintivos de la posmodernidad, relacionada con distintos ámbitos de la existencia humana. Uno de esos ámbitos es precisamente el arte posmoderno, en el que desembocan aceleradamente la sucesión de vanguardias. Tal aceleración se observa también, en la velocidad de transmisión de la información ligada al desarrollo computacional, velocidad que no necesariamente equivale a la profundidad. La velocidad nos acerca, pero también puede conducir al despeñadero... Es por ello que, desde la perspectiva de Lyotard, se puede sostener que el límite fundamental para la modernidad y, por tanto, para el arte moderno lo representa la ética. Más adelante se retoma esta idea de la ética como límite regulador, allende la tesis de que el arte no debe tener más límites que los que su propia naturaleza le imponga.

Si bien la crítica a la modernidad, desde el planteamiento de Lyotard (1980), se focaliza principalmente en el estudio de las sociedades del saber o comunidades epistémicas, en relación a su inserción en las sociedades altamente tecnológicas, tejiendo una crítica al saber científico que las justifica, también alcanza, como ya lo sugeríamos, a amplias dimensiones de la existencia humana, entre ellas a su dimensión estética y artística. Con respecto a esta relación entre tecnología y arte vale la pena citar a Paul Valéry quien, más profeta que el mismísimo Michel de Nôtre-Dame, en concordancia con Heráclito y su eterno principio del devenir, la transformación y la lucha de los opuestos, afirmaba lo siguiente:

Nuestras Bellas Artes fueron instituidas, y fijados sus géneros y su uso, en un tiempo muy distinto del nuestro, por hombres cuyo poder de acción sobre las cosas era insignificante comparado con el que nosotros poseemos. Pero el asombroso aumento de nuestros medios, la flexibilidad y la precisión que alcanzan, las ideas y los hábitos que introducen, nos aseguran de cambios próximos y muy profundos en la antigua industria de lo Bello. Hay en todas las artes una parte física que no puede ser mirada ni tratada como antaño, 
que no puede sustraerse a la acometividad del conocimiento y la fuerza modernos. Ni la materia ni el espacio ni el tiempo son de veinte años a esta parte lo que habían siempre sido. Hay que esperar que tan grandes novedades transformen toda la técnica de las artes, influyendo con ello la inventiva misma y quizá llegando hasta a modificar de una manera maravillosa la noción misma del arte. (Citado en Benjamin, 2013, p. 91).

¿La tecnología y el arte? La relación nos es casi natural en los tiempos actuales. Esto nos conduce a volver a la renacentista obra de Miguel Ángel, La creación de Adán, para establecer una relación de concubinato con el uso de herramientas digitales: el resultado es la polémica obra intitulada $L a$ creación de Batman de Vartan Garnikyan. ${ }^{14}$ No se hacen esperar los gritos escandalizados, perturbados y angustiados de las buenas y conservadoras conciencias, ante el ataque al eterno canon de belleza implicado en la innegablemente excelsa y original obra de Miguel Ángel, que es caricaturizada y mezclada con íconos televisivos y del cómic de la cultura pop contemporánea.

Los casos se multiplican: la quijotada de Ilan Stavans de trasladar a un código bastardo, el spanglish, que no se sitúa ni entre la jerga y el pidgin, la impoluta lengua de Cervantes, cuyo Quijote junto con las pinturas de Brueghel y las creaciones de Shakespeare inician la historia del arte moderno, según Hauser (1993, pp. 55-56); el descreimiento de Samuel Beckett mediante su novela Cómo es frente a la presentación de la eternidad y del cuasi-divino carácter del punto y la coma; el escatológico urinal de Marcel Duchamp; la infame caja de zapatos en la prestigiosa Bienal de Venecia...

¿Es La creación de Batman una obra de arte? A diferencia de La creación de Adán, que llevó años producirla, la obra de Garnikyan, que es en lo fundamental una copia, fue construida en meses, y "procesada" y "editada" por medios digitales. La obra de Garnikyan, en contraste con la original, carece de proporción, de balance, de apreciación sensitiva para el manejo del color de la profundidad y la perspectiva. Lo que es peor, como parte fundamental de "la mala copia", aparece, el ícono central de un superhéroe de la cultura pop, Batman, marcando en la obra su carácter

\footnotetext{
${ }^{14}$ La imagen está disponible en internet en la siguiente liga: https://www.demilked.com/starry-knight-classicalpaintings-batman-pop-art-vartan-garnikyan/
} 
ecléctico. Pero, ¿no se juzga equivocadamente? ¿No se están usando los propios criterios del arte moderno y, con mayor precisión, los del Renacimiento, para una obra que escapa e intenta negar precisamente esos criterios? ¿Qué es pues lo posmoderno, para poder adscribir esta obra a ese paradigma del arte? Lyotard, ahora en íntima relación con el artista y con la literatura, nos dice:

Un artista, un escritor posmoderno, están en la situación de un filósofo: el texto que escriben, la obra que llevan a cabo, en principio, no están gobernados por reglas ya establecidas, y no pueden ser juzgados por medio de un juicio determinante, por la aplicación a este texto, a esta obra, de categorías conocidas (Lyotard, 2005: 25).

Tal afirmación, en general, no es pertinente exclusivamente para el caso de la escritura o de la literatura, sino que alcanza al arte posmoderno en general como negador de "las reglas ya establecidas" para la elaboración de una obra. El arte moderno, una vez que se ha institucionalizado, postula un conjunto de valores y de reglas que ahora son negadas por una posmodernidad que "no encuentra su razón en la homología de los expertos, sino en la paralogía de los inventores" (Lyotard 1984, 10-11). El término “paralogía” que es usado por el pensador francés señala, desde una perspectiva lógica, un argumento inválido pero que se plantea ajeno al engaño consciente, a diferencia del sofisma. Esta idea de gobernar (fundamentar) el arte posmoderno en la paralogía, le permite a Lyotard oponerse frontalmente a las argumentaciones dadas para justificar el arte moderno desde una objetividad ligada a estructuras lógicas y a una metafísica del ser de la que ya hemos hablado ${ }^{15}$. Desde esa perspectiva, La creación de Batman no necesitaría de aquella objetividad lógica ni de aquella metafísica; no necesitaría de los metarrelatos, pues se justificaría precisamente como paralogía de su creador; la pintura sería entendida como un discurso paralógico y no estrictamente lógico, es decir, que no atiende al canon de belleza ni del Renacimiento ni del propio arte moderno.

Aquí, como antes, postulamos la complejidad de determinar en función de propiedades y características necesarias y suficientes el concepto mismo de "posmodernidad" en general y, de

\footnotetext{
${ }^{15}$ Tradicionalmente, en filósofos como Parménides, Platón y Aristóteles encontramos una ontología dual del ser y el noser en íntima relación con una lógica, también dual, que se estructura por los valores de verdad y falsedad.
} 
manera específica, el de "arte posmoderno". Al igual que en el arte moderno, consideramos más adecuado sostener que el conjunto de "estilos" asociados al arte posmoderno podrían ser explicados en términos de un continuo cuyos polos son, por un lado, "el arte moderno", y por el otro, "el arte posmoderno". Asimismo, según un conjunto de criterios y parámetros que, una vez más, deben ser discutidos de manera minuciosa y justificada, y que determinarían su "cercanía gradual", en relación al prototipo, con uno u otro de los polos, se puede delimitar con ello la especificidad de cada una de las obras que se quiera valorar ${ }^{16}$. Esta diferenciación gradual, como se señaló anteriormente, debe ser entendida también desde el concepto de prototipo ${ }^{17}$ :

\begin{tabular}{ccc}
\hline $\begin{array}{c}\text { Arte moderno } \\
\text { (La noche estrellada) }\end{array}$ & $\begin{array}{c}\text { Arte posmoderno } \\
\text { (La creación de Batman) }\end{array}$ \\
- & Innovación & ${ }^{18}$ \\
+ & Reglas y cánones & - \\
+ & Originalidad & - \\
- & Eclecticismo & + \\
- & (re)Producción de la obra y \\
comercialización & + \\
- & Participación del espectador como & + \\
- & parte de la obra de arte & + \\
- & Nihilismo & + \\
- & Significados de la obra & + \\
+ & Toma de acuerdos sobre el producto & -
\end{tabular}

En consecuencia, la ingente cantidad de estilos asociados tanto a las vanguardias del arte moderno como los estilos propiamente posmodernos podrían ser clasificados y explicados a partir de tales

\footnotetext{
${ }^{16}$ Ver nota 7.

${ }^{17}$ Reconocemos que se tendría que discutir si las obras mencionadas y trabajadas en el presente texto serían, de facto, más prototípicas que otras, para el arte renacentista, el arte moderno y el arte posmoderno.

${ }_{18}$ Al responder a la carencia de reglas universalmente válidas que fijen la producción artística, el arte posmoderno implicaría altos niveles de innovación, aunque tal innovación resultaría ser más anárquica que ordenada comparada con el arte moderno, es decir, dicha innovación estaría mucho menos determinada por los cánones artísticos ligados al arte renacentista y, en menor medida, al arte moderno.
} 
criterios, y los que deban ser añadidos: el expresionismo abstracto, el happening, el performance, el pop art, el minimalismo, el arte conceptual, la instalación, el arte performancero, el arte digital, el arte de apropiación, el arte intermedia y multimedia... De tal forma, la obra de Garnikyan, La creación de Batman podría ser clasificada aquí en varios sentidos a partir del modelo anterior, dados sus altos contenidos "eclécticos", la fusión y la mezcla de géneros, la "apropiación" de una obra de arte perteneciente a alguno de los grandes artistas de todos los tiempos, el uso de herramientas digitales y computacionales, el uso de íconos de la televisión y del cómic pertenecientes a la cultura pop, la utilización de recursos diversos de otros campos de la cultura popular, etcétera.

\section{La conclusión: El texto intermedio}

Sin las altas pretensiones teóricas de posicionarnos como jueces frente a la disputa, lo que implicaría la aceptación explícita, aunque quizás no incondicional, del modelo moderno, pero sin atender tampoco a las anárquicas y relativizadas presunciones de lo posmoderno, optamos personalmente por la vía del cobarde; aquella vía inmortalizada por Aristóteles y que, en español, podemos denominar como prudencia.

Ya los pre-modelos funcionales señalados en los dos apartados anteriores configurarían en más de algún sentido nuestra posición frente al dilema, que postula no la oposición absoluta de lo moderno y lo posmoderno, sino una oposición gradual, moderada: "más artístico", "menos artístico" en función de los criterios señalados, estableciendo la idea de que ambos paradigmas conviven en nuestro ser contemporáneo y que pueden ser comprendidos haciendo referencia a ejemplares prototípicos. En ese sentido, el ser arte absoluto vinculado con el Renacimiento y con la Modernidad se transforma en un ser arte en relación a diversos criterios. De tal manera que, lejos de una lógica dicotómica y excluyente, lo que parece ser arte pueda ser explicado y comprendido, dando lugar a la idea de que la apariencia también posee ser: el ser y el no-ser, la apariencia y la realidad serían los prototipos que posibilitarían una comprensión de los fenómenos difusos. 
Siguiendo ese orden de ideas, se afirma que la belleza, entendida ya sea de forma renacentista o de forma moderna, sigue manteniendo su poder y su fuerza, así como la proporción, la técnica depurada, etcétera, vinculadas con el arte moderno (homología); asimismo, resulta atractiva la rebeldía y la indecencia implicada en lo diverso (paralogía), rasgos que acompañan la valoración estética y artística posmoderna. Sin embargo, se sugería en líneas arriba la idea de que la ética puede ser entendida como un elemento básico que funcione a manera de límite regulador de las actividades humanas (no sólo del arte). En el caso de la modernidad, ese límite es representado históricamente por Auschwitz. ¿Y en el caso de la posmodernidad?

El ejemplo que comentamos como obra de arte posmoderno, si bien implica elementos de radicalidad, de subversión y de negación de ciertos valores asociados también con la modernidad, y su ejercicio del poder, se puede sostener que aún conserva determinados elementos que pueden ser valorados positivamente y que no están tan alejados del arte moderno, por ejemplo, en $L a$ creación de Batman se requieren habilidades mínimas como, por ejemplo, el saber dibujar, aunque quizás no a la manera de Miguel Ángel. Sin embargo, sabemos de la existencia de "obras de arte" que implican una radicalidad que, según nuestra perspectiva, atenta contra valores esenciales de la humanidad como la vida misma. Como ejemplo de ello se puede pensar en Guillermo Vargas, alias Habacuc, quien montó una exposición en Nicaragua en 2007 que consistió en amarrar a un perro callejero, enfermo y hambriento, al cual presuntamente dejó morir (Cfr. Ortega, 22 de octubre de 2007). La determinación de lo artístico y la producción de obras y experiencias, estéticas o artísticas, aún refiriendo a la noción de prototipo, ocupa un lugar secundario cuando el mantenimiento de la vida se encuentra de por medio. Al respecto, no hay que olvidar que, asociada a los desastres del nazismo y del fascismo, se encontraba una "estética de la destrucción" que hacía apología de la muerte ${ }^{19}$. Así, pues, la ética fungiría no como un regulador del arte, sino como el límite del mismo si se quiere evitar aquella destrucción de lo diverso implicada en el concepto heraclíteo del devenir.

\footnotetext{
${ }^{19}$ Se sugiere aquí que un rasgo semántico fundamental del concepto de vida es la diversidad. En ese sentido, el fascismo, y sus variantes ideológicas, implican la negación de la vida en tanto que se niega la diversidad. El arte y la experiencia estética propugnadas por el fascismo tienden a la homogenización, a la uniformidad estilística y al exterminio de la libertad y de la personalidad individual. Sobre la estética del fascismo, se puede revisar la visión del teórico del arte Werner Haftmann (1957).
} 
El optimismo moderno, con sus grandes relatos emancipatorios, terminó en la autofagia en íntima relación con aquella estética uniforme del fascismo. Por su parte, el nihilismo posmoderno, casi por definición, apunta también a la autofagia posibilitando una estética de una anarquía uniforme solapada por el capital. Si las artes, el humanismo y las humanidades están ancladas a la modernidad, expresiones como "poshumanismo", "posmodernidad", "arte posmoderno" y semejantes, son las huellas indelebles de la negación de las primeras, consolidándose así "la muerte del arte" (Cfr. Vatimo, 2007, pp. 49-60) por un proceso de autofagia ${ }^{20}$ : el propio desarrollo histórico del arte conduciría a éste a su extinción...

Finalmente, nos remitimos a la siguiente cita para estructurar el comentario final que constituye, en lo fundamental, el texto intermedio de la discusión:

\begin{abstract}
No creo (...) que la racionalidad esté definida por un conjunto de "cánones" o "principios" invariables; los principios metodológicos están conectados con nuestra concepción del mundo, incluyendo la concepción de nosotros como parte del mundo, y cambian con el tiempo. En estos términos estoy de acuerdo, con los filósofos subjetivistas en que no hay ningún órganon fijo y ahistórico que defina el ser racional; pero no concluyo, por el hecho de que nuestras concepciones de la razón evolucionen en la historia, que la razón en sí puede ser (o evolucionar hasta convertirse en) cualquier cosa (...). (Puntam, citado por Bouveresse, 1989, p. 81).
\end{abstract}

De la misma manera, se puede sostener que el arte no está definido, ni siquiera teóricamente, por un órganon fijo e independiente de la historia, sino que está circunscrito, como todo lo humano, a las contingencias provocadas por el caudaloso río de Heráclito. La propia idea del devenir garantiza el alejamiento de la uniformidad y la vindicación de la diversidad, característica inherente a la vida. Sin embargo, también se puede afirmar que nuestra concepción del arte en sí no puede evolucionar en cualquier cosa; por ejemplo, no puede evolucionar en la infame exhibición de la negación de la vida, como el caso antes mencionado del cánido. Aquí, la tolerancia no debe tolerar a la intolerancia (Cfr. Žižek, 2008).

\footnotetext{
${ }^{20}$ La figura de la "autofagia" está tomada de Jacques Bouveresse (1989), quien la aplica en la descripción del filósofo.
} 
Nuestra posición frente al dilema se visualiza pues en el continuo funcional que va de un polo (Miguel Ángel) al otro polo (Batman), del arte moderno al arte posmoderno. Se presenta así no una diferencia esencialista y absoluta, sino divergencias graduales medidas en diversos criterios y parámetros y que están fundamentadas en formas de la cognición humana asociadas a los prototipos.

\section{Referencias}

Benjamin, W. (2013). Sobre la fotografía. Valencia: Editorial Pre-textos.

Bouveresse, J. (1989). El filósofo entre los autófagos. México: Fondo de Cultura Económica.

Dilthey, W. (1949). Introducción a las ciencias del espíritu. México: Fondo de Cultura Económica.

Haftmann, W. (1957). Painting. En Ritchie, A. C. (Ed.). German art of the XXth century. New York: The Museum of Modern Art.

Hauser, A. (1993). Historia social de la literatura y del arte. Tomo II. (22a edición). Barcelona: Editorial Labor. Hauser, A. (1982). Origen de la literatura y del arte modernos. I. El manierismo, crisis del Renacimiento. (4a edición). Barcelona: Editorial Labor.

Kuhn, T. S. (1971). La estructura de las revoluciones científicas. México: Fondo de Cultura Económica.

Lakoff, G. (1982), Categories. An essay in Cognitive Linguistics. En Linguistic Society of Korea (Ed.). Linguistics in the Morning Calm. Seoul: Hanshin.

Lyotard, J-F. (2005). La posmodernidad (Explicada a los niños). Barcelona: Gedisa.

Lyotard, J-F. (1999). La diferencia. Barcelona: Gedisa.

Lyotard, J-F (1984). La condición posmoderna. (9ạ edición). Madrid: Editorial Cátedra.

Lyotard, J-F. (1980). Les problèmes du savior dans les sociétés industrielles les plus développes. Québec:

Gouvernement du Québec, Conseils des universités

Méndez, M. y Ramírez, C. (2017), Lo racional y lo razonable: crítica a los planteamientos posmodernos de J. F.

Lyotard. En Mayorga, C.; Nava, J.M. y Ramírez, C. (Eds.). Argumentación y tipos de racionalidad.

Guadalajara: Universidad de Guadalajara.

Mondolfo, R. (1966). Héraclito. Textos y problemas de su interpretación. México: Siglo XXI.

Nava, J.M. y Méndez, M. (2018). Carpeta de apuntes filosóficos. Guadalajara: Universidad de Guadalajara.

Oesterreicher, W. (2004). Textos entre inmediatez y distancia comunicativas. El problema de lo hablado escrito en el siglo de oro. En Cano, R. (ed.), Historia de la lengua española. Barcelona: Editorial Ariel. 
O’Gorman, E. (1984). La invención de América. Investigación acerca de la estructura del mundo y del sentido de su devenir. México: Secretaría de Educación Pública.

Ortega, J. (1998). La deshumanización del arte y otros ensayos de arte. Madrid: Alianza Editorial.

Ortega, J. (22 de octubre 2007). Un "artista" mata de hambre a un perro en una exposición. Equinoxio.

Recuperado de: https://www.equinoxio.org/estancias/un-artista-deja-morir-a-un-perro-en-unaexposicion-1979/

Paz, O. (2014). Excursiones e incursiones: dominio extranjero. Fundación y disidencia: dominio hispánico. Obras completas II. México: Fondo de Cultura Económica.

Platón. (1988). Diálogos. Parménides, Teeteto, Sofista, Político. V. Madrid: Gredos.

Rosch, E. (1978), Principles of categorization. En Rosch, E. \& Lloyd, B. (eds.). Cognition and Categorization. Hillsdale, New Jersey: Lawrence Erlbaum Associates.

Rosch, E. \& Mervis, B. (1975) "Family Resemblances: Studies in the Internal Structure of Categories".

Cognitive Psychology, (7), 573-605.

Seiler, H. (2001). The Cologne UNITYP project. En Haspelmath, M., König, E., Oesterreicher, W., \& Raible, W. (eds.). Language Typology and Language Universalien. Sprachtypologie und sprachliche Universalien. La typologie des langes et les universaux linguistiques. Berlin/Nueva York: De Gruyter.

Stevens, W. (1945). Description without Place [Poem]. The Sewanee Review, 53(4), 559-565. Recuperado de http://www.jstor.org/stable/27537622

Vatimo, G. (2007). El fin de la modernidad. Nihilismo y hermenéutica en la cultura posmoderna. Barcelona: Gedisa.

Wittgenstein, L. (1988). Investigaciones filosóficas. Barcelona: Ediciones Altaya.

Žižek, S. (2008). En defensa de la intolerancia. Madrid: Ediciones sequitur. 